УДК 676.1.054.1

\title{
ВОПРОСЫ СНИЖЕНИЯ ПОЖАРНОЙ ОПАСНОСТИ ДРЕВЕСНОВОЛОКНИСТЫХ ПЛИТ
}

\author{
() Д.В. Иванов ${ }^{1,2 *}$, Н.А. Петрушева ${ }^{3}$ Ю.Д. Алашкевич ${ }^{1,2}$ \\ ${ }^{1}$ Сибирский государственный технологический университет, пр. Мира, 82, \\ Красноярск, 660049 (Россия), e-mail: sibstu@sibstu.kts.ru \\ ${ }^{2}$ Сибирская пожарно-спасательная академия ГПС МЧС России, \\ ул. Северная, 1, Железногорск, 662972 (Россия), e-mail: info@lfsibgtu.ru \\ ${ }^{3}$ Лесосибирский фрилиал Сибирского государственного технологического \\ университета, ул. Победы, 29, Лесосибирск, 662543 (Россия), \\ e-mail: info@lfsibgtu.ru
}

Работа представляет собой результат аналитического обзора теоретических и экспериментальных данных в области снижения пожарной опасности древесно-плитных материалов. Несмотря на большое число исследований в данной области некоторые ее аспекты остаются незатронутыми, в частности вопросы снижения пожарной опасности древесноволокнистых плит мокрого способа производства. Большая часть исследований посвящена теме снижения пожарной опасности древесностружечных плит и древесноволокнистых плит сухого способа производства. Технологические решения, приемлемые для данных производств, не подходят для производства древесноволокнистых плит мокрым способом из-за специфических условий (высокой влажности) протекания большинства технологических операций. Несмотря на устойчивое мнение, что введение в древесноволокнистую плиту только минеральных наполнителей является малоэффективным, в 2013 г. была запатентована композиция для производства древесноволокнистых плит со сниженной пожарной опасностью. Патент был основан на результатах исследований, проводимых в СибГТУ А.В. Антоновым и др. Однако А.В. Антонов в своей диссертационной работе не затрагивает вопросы, связан с процессом размола технологической щепы и волокнистого полуфабриката. Известно, что качество древесноволокнистой массы оказывает большое влияние на качество готовой древесноволокнистой плиты. В свою очередь, качество древесноволокнистого полуфабриката определяется параметрами процесса размола. Таким образом, основным направлением дальнейших исследований с целью совершенствования технологии производства ДВП со сниженной пожарной опасностью, с нашей точки зрения, является разработка принципиально новой гарнитуры для ножевых размалывающих машин.

Ключевые слова: древесноволокнистая плита, пожарная опасность, специальные свойства плитных материалов.

\section{Введение}

Известно, что древесноволокнистые плиты (ДВП) - листовой материал, изготавливаемый из переплетенных между собой и сформированных в ковер влажных или сухих древесных волокон посредством горячего прессования или сушки [1]. Авторы учебников по производству древесноволокнистых плит [2-5] классифицируют древесноволокнистые плиты следующим образом: 1) по способу производства - мокрого,

Иванов Дмитрий Владимирович - заместитель начальника отдела планирования, организации и координации научноисследовательской деятельности научно-технического центра, e-mail: ivanov.dv.sib@mail.ru

Петрушева Надежда Александровна - доцент кафедры технологии лесозаготовительных

и деревоперерабатывающих производств, кандидат технических наук, e-mail: info@lfsibgtu.ru

Алашкевич Юрий Давыдович - заведующий кафедрой машин и аппаратов промышленных технологий, доктор технических наук, профессор, e-mail: mapt @ sibstu.kts.ru сухого, мокро-сухого и полусухого способов; 2) по твердости и прочности - сверхтвердые, твердые, полутвердые и мягкие, а также плиты средней плотности; 3) по назначению - общего назначения, для изготовления деталей к автомобилям, для покрытия полов, для устройства санитарно-технических кабин и др.; 4) со специальными свойствами - огнестойкие, биостойкие, атмосферостойкие, звукопоглощающие, битуминированные, трудносгораемые.

\footnotetext{
* Автор, с которым следует вести переписку.
} 
Древесноволокнистые плиты общего назначения нашли свое применение в различных отраслях промышленности, строительстве, производстве мебели, тары и других областях. Мягкие ДВП используют в качестве термо- и звукоизоляции в промышленном и гражданском строительстве [6]. Твердые ДВП используются в качестве листового обшивочного материала для каркасных перегородок, стен, потолков зданий с последующей их окраской или оклейкой обоями. В производстве мебели широко применяют древесноволокнистые плиты средней плотности (ДВП-СП). Из тонких ДВП изготовляют ящики посылочного типа, тару для небольших грузов. Из плит повышенной толщины изготовляется транспортная тара для изделий машиностроения. Некоторое количество плит расходуется для ремонтных нужд, а также для продажи населению.

Однако в настоящее время требования к пожарной и экологической безопасности, стойкости плитных материалов к биологическим поражениям и воздействию влаги, прочностным характеристикам все более ужесточаются. В современных условиях наиболее востребованными и конкурентоспособными становятся плиты специального назначения [7].

\section{Основная часть}

Специальные свойства древесных плит определяются конкретными особенностями их применения. Благодаря этим свойствам они используются в определенных условиях службы, обеспечивая выполнение специфических требований. Такие дополнительные свойства плит достигаются путем модифицирования направленного изменения состава или структуры древесного комплекса или введения добавок в композицию материала без их химического взаимодействия, но с обязательным получением нового качества [8].

Водостойкие плиты обладают формоустойчивостью в процессе эксплуатации при непостоянных параметрах микроклимата, что достигается в процессе проклеивания древесноволокнистой композиции и пропитки готовой продукции [9].

Ударопрочные древесные плиты в определенных пределах устойчивы к действию ударных нагрузок благодаря высокой динамической вязкости. Основные показатели ДВП по прочности достигаются путем их пропитки высыхающими или полувысыхающими маслами [9].

Биостойкие плиты обладают устойчивостью к действию дереворазрушающих грибов. Для придания биостойкости в древесноволокнистую композицию добавляют антисептики различного химического состава [9-11].

Огнезащищщенные древесные плиты дополнительно обладают свойством неспособности к самостоятельному горению. Теоретические и экспериментальные исследования по вопросам снижения пожарной опасности древесных плит ведутся в нашей стране и за рубежом уже на протяжении 60 лет [12-22]. За это время были разработаны и предложены различные способы снижения пожарной опасности древесноволокнистых плит [15, 16, 19, 23, 24].

Огнезащитная обработка готовых плит получила распространение благодаря простоте организации работ. Она не связана с необходимостью изменения технологического процесса изготовления плит и может осуществляться потребителями. Для снижения горючести и пожаростойкости материалов и конструкций широко используются огнезащитные краски. Наиболее эффективными и перспективными из них являются органические покрытия вспучивающегося (интумесцентного) типа. Огнезащитные вспучивающиеся краски представляют собой достаточно сложные многокомпонентные системы, поскольку в их состав, наряду с традиционными компонентами обычных красок, входят интумесцентные системы, включающие три основных компонента: катализатор коксообразования, коксообразующий и вспенивающий агенты [17]. Катализатором обычно используют фосфорсодержащие соединения, и чаще всего аммоний полифосфат (АПФ). В качестве сырья для образования углеродного каркаса вспененного слоя, как правило, используют полиспирты, а в качестве порофоров - органические амины или амиды, выделяющие при повышенных температурах негорючие газы - углекислый, азот, аммиак, вспенивающие системы. Наиболее популярными из полиспиртов в таких составах является пентаэритрит, а из аминов - меламин.

Интумесцентная технология защиты изделий от воздействия пламени заключается в комбинации коксообразования и вспучивания лакокрасочного защитного покрытия под воздействием высоких температур. Образующийся вспененный ячеистый коксовый слой предохраняет окрашенную поверхность от воздействия теплового потока или пламени [14]. Однако при всех достоинствах поверхностная обработка плит - низкопроизводительная и трудоемкая операция [13]. 
Более эффективна в отношении огнезащиты пропитка твердых плит. Для ускорения процесса пропитки применяют метод горяче-холодных ванн или пропитку под давлением в автоклавах. Пропитка с применением ультразвука или без него приводит к частичному разрушению межволоконных связей и закономерно снижает прочность плит. Степень восстановления прочности при последующей сушке (закалке) обусловлена свойствами огнезащитного состава. Если состав способен вступать во взаимодействие с древесным волокном, прочность плит возрастает. Данные о реакционной способности огнезащитного состава приведены в [13]. Все же из-за отрицательного влияния на прочность и формостабильность плит пропитка применяется весьма ограниченно [17].

Наиболее перспективным считается придание огнестойкости древесноволокнистым плитам в процессе их изготовления [15]. Среди известных технических решений наиболее теоретически обосновано использование фосфор-, азот- и бромсодержащих антипиренов с регулируемой кислотностью [13, 23, 24]. Например, в лаборатории ОАО «Уралхимпласт» были получены бромпроизводные карданола и бромированная карданолсодержащая новолачная смола (БКНС); исследованы состав, строение и огнезащитная эффективность бромпроизводных соединений; исследованы процессы, протекающие при термическом воздействии на БКНС. Древесностружечные плиты (ДСтП), изготовленные с использованием в качестве адгезива бромированной карданолсодержащей полиуретановой Резикард БР, представляют собой материал повышенной огнестойкости, удовлетворяющий требованиям класса Р7 по EN 312 (особо прочные влагостойкие ДСтП) и требованиям класса эмиссии SuperE0 [23, 24].

Анализ работ в данной области показал, что основной упор делается на ДСтП и ДВП сухого способа производства - снижение горючести достигается введением в состав древесных композиций антипиренов путем обработки древесных частиц данными веществами [14]. Вещества эти изменяют характер термического разложения древесины в процессе горения [17].

Принципиальная технологическая схема изготовления огнезащищенных древесноволокнистых плит сухим способом была разработана Н.Я. Солечником и А.А. Леоновичем [19]. Совместно с НПО «Союзнаучплитпром» была создана промышленная технология. Древесноволокнистые плиты сухого способа изготовления, получаемые с использованием разработанной рецептуры огнезащитного состава, получили название плиты О-ДВП. По заключению ВНИИПО им была присвоена по ГОСТ 17088-71 группа трудногорючих материалов.

Однако данный способ снижения пожарной опасности не подходит для ДВП мокрого способа производства. Специфика производства ДВП мокрым способом заключается в том, что технологические операции, в процессе которых могла бы осуществляться обработка древесных частиц антипиренами, - приготовление, проклеивание древесноволокнистой массы, формирование ковра - производятся в условиях высокой влажности. Это существенно усложняет введение водорастворимых антипиренов в состав древесноволокнистой композиции; водонерастворимые же вещества малоэффективны в качестве антипиренов и, кроме того, оказывают негативное воздействие на физико-механические свойства готовой продукции [13].

В 1962 г. Всесоюзным научно-исследовательским институтом целлюлозно-бумажной промышленности (ВНИИБ) была разработана технология изготовления огнезащищенных плит мокрым способом. Она основывается на применении водонерастворимых двойных солей фосфорной кислоты - железоаммонийфосфата и магнийаммонийфосфата. В промышленных условиях применяют побочный продукт выработки фосфатов аммония - аммофосы. В мешальном бассейне массу перемешивают с аммофосами, отливают периодическим способом и прессуют. Для соединения не взаимодействующих с древесным волокном добавок дополнительно вводят синтетические связующие. Такие плиты получили название «Рамолит» [19]. На бумажной фабрике №1 им. М. Горького (Ленинград) была предпринята попытка выпуска огнезащищенных плит «Рамолит-1». Однако плиты обладали низкой прочностью, водопогощение техническими условиями не регламентировалось и выбранные в качестве антипирена добавки оказались малоэффективными [13], в связи с чем производство плит было свернуто.

В 2010-2013 гг. в лаборатории лесоперерабатывающей, целлюлозно-бумажной и химической технологии древесины Лесосибирского филиала СибГТУ и в промышленных условиях завода ДВП ОАО «Лесосибирский ЛДК №1» был проведен ряд экспериментальных исследований по снижению пожарной опасности ДВП мокрого способа производства [21, 25-31]. Для снижения горючести плит в состав древесноволокнистой композиции вводился вспученный вермикулит. Несмотря на устойчивое мнение, что введение в древесноволокнистую плиту только минеральных наполнителей - асбестового волокна, гипса, вермикулита, стекловолокна - является малоэффективным, так как требуемая степень огнестойкости достигается 
при введении значительных количеств наполнителя [5, 12], результаты проведенных исследований позволили предложить композицию для производства древесноволокнистых плит со сниженной пожарной опасностью [31], а также технологию производства данного вида продукции.

Однако А.В. Антонов в своей работе [21] не затрагивает ряд вопросов, которые, на наш взгляд, требуют пристального внимания, такие как механизм взаимодействия вспученного вермикулита и древесных волокон; морфологическая структура древесноволокнистой массы для производства ДВП со сниженной пожарной опасностью; фильтрационные свойства ковра при его формировании при введении вспученного вермикулита; энергозатраты на технологический процесс. Названные аспекты производства ДВП напрямую связаны с процессом размола технологической щепы и волокнистого полуфабриката.

Известно, что качество древесноволокнистой массы оказывает большое влияние на качество готовой древесноволокнистой плиты. В свою очередь, качество древесноволокнистого полуфабриката определяется параметрами процесса размола. Размол древесины - одна из ответственных операций в технологии производства древесноволокнистых плит $[2,3,33]$. Цель размола - активировать поверхность волокон таким образом, чтобы функциональные группы, расположенные на поверхности, были в состоянии взаимодействовать между собой на расстояниях, необходимых для молекулярного взаимодействия, и обеспечить механическую прочность, способность к разбуханию, объемный вес, воздухопроницаемость и другие свойства $[2,33,38]$.

Размол может осуществляться различными способами с применением различного типа ножевого и безножевого оборудования [37, 43, 44, 46]. На современном этапе производства ДВП мокрым способом получение древесноволокнистого полуфабриката преимущественно осуществляется путем размола щепы в две ступени на быстроходных дисковых мельницах [54]. Широкое использование указанного вида оборудования в плитном производстве объясняется тем, что в дисковых размалывающих машинах можно получить волокна с более высокими морфологическими свойствами, чем, скажем, в дефибрерах [36-48]. Главными управляемыми факторами процесса размола волокнистых полуфабрикатов является продолжительность размола и удельное давление на волокно, создаваемое в зоне размола, или удельная нагрузка на кромки ножей [49].

Варьируя управляемыми факторами процесса размола, исследователь может изменять основные показатели, характеризующие качество древесной массы [46, 49-52]: степень помола массы, фракционный показатель качества степени помола массы, объемный вес массы, механическую прочность массы, отношение длины волокна к диаметру, объем волокна, размерную и структурную неоднородность массы.

Необходимость правильного подбора размалывающей гарнитуры с требуемой длиной ножей и шириной канавок, а также угла пересечения ножей ротора и статора отмечают в своей статье В.Е. Гурьянов, Л.И. Семкина, Т.Н. Псумякова [53], выделяющие указанные параметры как необходимые для оптимизации режима размола, степени помола и выбора концентрации размалываемой массы с целью получения высококачественной готовой продукции и снижения затрат электроэнергии.

В ножевых размалывающих машинах доля рубленого волокна и волокна, подверженного ударным нагрузкам, может регулироваться рядом технологических факторов процесса размола, в числе которых общепризнанные факторы: время обработки, вид обрабатываемого материала, концентрация массы, удельное давление в зазоре между ножами или величина зазора и др. Но основным фактором, влияющим на качество помола в ножевых размалывающих машинах, кроме перечисленных выше, является характер распределения усилия как на кромках ножевой гарнитуры, так и на поверхностях сопряжения при скрещивании ножей ротора с ножами статора. Характер распределения этих усилий зависит в первую очередь от расположения ножей ротора и статора относительно друг друга. Для обеспечения основных ударных воздействий при контакте ножей необходимо создать условия, при которых угол скрещивания пересекающихся ножей при на бегании рабочих поверхностей ротора на рабочие поверхности статора приближался бы к нулю.

\section{Выводы}

Принимая во внимание все вышеизложенное, можно сказать, что основным направлением дальнейших исследований с целью совершенствования технологии производства ДВП со сниженной пожарной опасностью, с нашей точки зрения, является разработка принципиально новой гарнитуры для ножевых размалывающих машин. Применение данной гарнитуры должно обеспечить получение волокнистого полуфабриката с такими показателями, которые позволят производить высококачественные древесноволокнистые плиты специального назначения. 


\section{Список литературы}

1. Чистова Н.Г. Переработка древесных отходов в технологическом процессе получения древесноволокнистых плит : дис. ... д-ра техн. наук. Красноярск, 2010. 461 с.

2. Ребрин С.П., Мерсов Е.Д., Евдокимов В.Г. Технология древесноволокнистых плит : 2-е изд., перераб. и доп. М., 1982. 272 c.

3. Мерсов Е.Д. Производство древесно-волокнистых плит : учеб. пособие. М., 1989. 232 с.

4. Бекетов В. Д. Повышение эффективности производства древесноволокнистых плит. М., 1988. 160 с.

5. Волынский В.Н. Технология древесных плит и композитных материалов : учебно-справочное пособие. СПб., 2010. $336 \mathrm{c}$.

6. Лесные ресурсы России. Международный транслятор национальных стандартов на основные виды лесной продукции / под ред. И. В. Воскобойникова. М., 1994. 562 с.

7. Челышева И.Н. Совершенствование технологии производства твердых древесноволокнистых плит повышенной водостойкости : дис. ... канд. техн. наук. Красноярск, 2007. 151 с.

8. Технология целлюлозно-бумажного производства. В 3 т. Т. ІІ. Производство бумаги и картона. Ч. 2. Основные виды и свойства бумаги, картона, фибры и древесных плит. СПб., 2006. 499 с.

9. Ломакин А.Д. Защита древесины и древесных материалов. М., 1990. 256 с.

10. Патент 2033489 (РФ). Способ изготовления биостойкой древесноволокнистой плиты / М.П. Гаврилов. 1995.

11. Иванов Ф.М. Биоповреждения в строительстве. М., 1984. 320 с.

12. Леонович А.А. Снижение пожарной опасности древесных материалов, изделий и строительных конструкций. СПб., 2002. $59 \mathrm{c}$.

13. Леонович А.А. Огнезащита древесных плит и слоистых пластиков. М., 1974. 128 с.

14. Леонович А.А. Древесные плиты специального назначения. СПб., 2007. 96 с.

15. Патент 2352601 (РФ). Способ получения теплоизоляционного и огнестойкого многослойного комбинированного полимерного покрытия / В.В. Беляев, И.М. Федотов, 2009.

16. Rayham E.A. Fibre building board, fire and future // Fire Prot. Rev. 1975. Vol. 38, N411. Pp. 67-74.

17. Шапиро А.Д. Способы придания древесноволокнистым плитам огнезащитных свойств. М., 1962. 56 с.

18. Леонович А.А. Огнезащита древесноволокнистых плит с применением солей ортофосфорной кислоты // Материалы науч.-тех. конф. ЛТА. Л., 1966. С. 64-70.

19. А.С. 195626 (СССР). Способ изготовления твердых древесноволокнистых плит / Солечник Н.Я., Леонович А.А. 1967.

20. Забродкин А.Г. Получение трудносгораемых древесностружечных плит // Новое в технике и технологии древесностружечных плит. М., 1972. С. 72-76.

21. Антонов А.В. Производство древесноволокнистых плит с пониженной пожарной опасностью : дис. ... канд. техн. наук. Красноярск, 2013. 128 с.

22. Балакин В.М., Селезнев А.М., Белоногов К.В. Первичная оценка огнезащитных свойств вспучивающихся покрытий на основе различных водных дисперсий // Пожаровзрывобезопасность. 2010. Т. 19, №6. С. 14-19.

23. Шишлов О.Ф., Дождиков С.А., Ельцов О.С., Уломский Е.Н., Глухих В.В., Стоянов О.В. Изучение синтеза бромпроизводных карданола и их эффективности в качестве антипирена для древесных материалов // Все материалы. Энциклопедический справочник. 2013. №10. С. 47-55.

24. Дождиков С.А. Получение древесных композиционных материалов с карданолсодержащими новолачными смолами : дис. .... канд. техн. наук. Екатеринбург, 2014. 130 с.

25. Антонов А.В., Алашкевич Ю.Д., Петрушева Н.А., Чижов А.П. Получение древесноволокнистых плит специального назначения с использованием вермикулита // Древесные плиты: теория и практика : сб. ст. по материалам XIV междунар. науч.-практ. конф. СПб., 2011. С. 71-73.

26. Антонов А.В., Петрушева Н.А., Алашкевич Ю.Д. Получение огнезащищенных древесноволокнистых плит // Лесной журнал. 2012. №4. С. 99-104.

27. Антонов А.В., Петрушева Н.А., Чижов А.П., Алашкевич Ю.Д. Влияние технологических и конструктивных параметров размола на свойства трудновоспламеняемых древесноволокнистых плит // Химия растительного сырья. 2012. №4. С. 215-219.

28. Антонов А.В., Петрушева Н.А., Чижов А.П., Алашкевич Ю.Д. Размол древесноволокнистых полуфабрикатов при производстве трудновоспламеняемых древесноволокнистых плит // Химия растительного сырья. 2012. №4. C. 221-224.

29. Антонов А.В., Алашкевич Ю.Д., Петрушева Н.А., Чижов А.П. Обоснование использования вермикулита в производстве ДВП со специальными свойствами // Новые достижения в химии и химической технологии растительного сырья: материалы V Всеросс. конф. с междунар. участием. Барнаул, 2012. С. 429-432.

30. Антонов А.В., Алашкевич Ю.Д., Петрушева Н.А., Чижов А.П. Математическая модель получения ДВП со специальными свойствами // Новые достижения в химии и химической технологии растительного сырья : материалы V Всеросс. конф. с междунар. участием. Барнаул, 2012. С. 427-429.

31. Патент 2486054 (РФ). Композиция для получения огнезащищенных древесноволокнистых плит / Н.А. Петрушева, Чистова Н.Г., Чижов А.П., Алашкевич Ю.Д., Финк И.А., Антонов А.В. 2013.

32. Дроздов И.Я, Кунин В.М. Производство древесноволокнистых плит. М., 1975. 328 с.

33. Иванов С.Н. Технология бумаги. Л., 1970. 695 с.

34. Steenberg B. Review of the Effect of Mechanica // Svensk Pappers-tidnirg. 1963. Vol. 66, N22. Pp. 933-939.

35. Chiaverina I. Proceedings of the II the Annual Pulp and Paper Conterence. Kalamaz. 1967. Pp. 73-79.

36. Алашкевич Ю.Д. Исследование гидродинамических явлений в процессе размола волокон в ножевых и размалывающих машинах : дис. ... канд. техн. наук. Л., 1970. 143 с.

37. Легоцкий С.С., Гончаров В.Н. Размалывающее оборудование и подготовка бумажной массы. М., 1990. 224 с.

38. Корда И., Либнар 3., Прокоп И. Размол бумажной массы. М., 1967. 402 с. 
39. Мейнандер П.О. С использованием компактной системы подготовки массы // Целлюлоза. Бумага. Картон. 2004. №8. C. 11-14.

40. Patent 5868330 (USA). Refiner disc with localized surface roughness : / Dodd J., Wasikowski P.1999.

41. Apl. 19547069 (DE). Verfahren zur Mahlung von Papierfasern / Meltzer F.P., Schneid J. 1997.

42. Clark James D.A. Fibrillation free water and fiber bonding // Tappi. 1969. N2. Pp. 335-340.

43. Пашинский В. Ф. Машины для размола волокнистой массы. М., 1972. 160 с.

44. Гончаров В.Н., Гаузе А.А., Аликин В.П. Машины для роспуска и безножевого размола бумажной массы. Л., 1979. $106 \mathrm{c}$.

45. Уханова Г.В., Ласкеев П.Х., Липцев И.В. Изменение реологических свойств древесины в процессе гидротермической обработки при производстве древесноволокнистых плит // Сборник трудов ВНИИДрев. 1973. Вып. 6. С. 15-19.

46. Ласкеев П.Х. Производство древесной массы. М., 1967. 580 с.

47. Лаптев В.Н. Производство древесной массы: учеб. пособие. СПб., 2009. 48 с.

48. Обливин А.Н. Перспективы развития технологии древесных плит // Деревообрабатывающая промышленность. 2000. №3. С. 6-11.

49. Алашкевич Ю.Д. Основы теории гидродинамической обработки волокнистых материалов в размольных машинах : дис. ... д-ра техн. наук. Красноярск, 1986. 170 с.

50. Гончаров В.Н. Теоретические основы размола волокнистых материалов в ножевых машинах : дис. ... д-ра техн. наук. Л., 1990. 433 с.

51. Липцев Н.В. Теоретические основы технологии древесноволокнистой массы и пути повышения эффективности производства древесноволокнистых плит: автореф. дис. ... д-ра техн. наук. Л., 1982. 39 с.

52. Пен Р.З. Технология древесной массы. Красноярск, 1998. 220 с.

53. Гурьянов В.Е., Семкина Л.И., Псумякова Т.Н. Оптимизация условий размола беленой березовой целлюлозы на дисковых мельницах // Бумажная промышленность. 1990. №10. С. 11.

54. Леонович А.А. Технология древесных плит: прогрессивные решения : учеб. пособие. СПб., 2005. 208 с.

Поступило в редакцию 24 июня 2015 г.

После переработки 21 декабря 2015 г. 
Ivanov D.V. ${ }^{1,3^{*}}$, Petrusheva N.A. ${ }^{2}$, Alashkevich Iu.D. ${ }^{1,3}$ QUESTIONS TO REDUCE THE RISK OF FIRE FIBREBOARD

${ }^{I}$ Siberian State Technological University, Mira ave., 82, Krasnoyarsk, 660049 (Russia), e-mail: sibstu@ sibstu.kts.ru

${ }^{2}$ Siberian Fire and Rescue Academy State Fire Service of the Ministry of the Russian Federation for Civil Defense,

Emergencies and Elimination of Consequences of Natural Disasters, Severnaia st., 1, Zheleznogorsk, 662543 (Russia),

e-mail: info@lfsibgtu.ru

${ }^{3}$ Lesosibirsky branch of the Siberian State Technological University, Pobedy st., 29, Lesosibirsk, 662543 (Russia),

e-mail: info@lfsibgtu.ru

The work represents the result of the analytical review of theoretical and experimental research in the area of reducing fire hazard of wooden boards. Despite the large number of studies in this field some of its aspects remain unaffected, in particular, the reduction of fire hazard wood fiberboards of wet production method. The bulk of research devoted to the reduction of fire risk of chipboards and hardboard dry method of production. Technological solutions, acceptable for these industries are not suitable for the production of fiberboard wet method because of the specific conditions (high humidity) the occurrence of most manufacturing operations. In spite of the strong opinion that the introduction of wood-fiber plate only mineral fillers is ineffective, in 2013, was patented a composition for the production of fibreboard with reduced fire hazard. The patent was based on the results of research conducted in the Siberian state technological University A. V. Antonov, etc., However, A. V. Antonov, in his doctoral thesis work does not raise issues related to the process of grinding wood chips and fibrous semi-finished product. It is known that the quality of wood-fiber mass has a great influence on the quality of the finished fibreboard. In turn, the quality of wood-fiber semi-finished product is determined by the parameters of the milling process. Thus, the main direction of further research to improve the technology of production of fiberboard with a reduced fire hazard, from our point of view, is to develop a fundamentally new headset for knife grinding machines.

Keywords: fiberboard, fire hazard, the special properties of plate materials.

\section{References}

1. Chistova N.G. Pererabotka drevesnykh otkhodov v tekhnologicheskom protsesse polucheniia drevesnovoloknistykh plit : dis. ... d-ra tekhn. nauk. [Recycling wood waste in the process producing fibreboard: the dissertation of the doctor of technical sciences]. Krasnoyarsk, 2010, 461 p. (in Russ.).

2. Rebrin S.P., Mersov E.D., Evdokimov V.G. Tekhnologiia drevesnovoloknistykh plit. [Technology fibreboard]. Moscow, 1982, 272 p. (in Russ.).

3. Mersov E.D. Proizvodstvo drevesno-voloknistykh plit. [Manufacture of fibreboard]. Moscow, 1989, 232 p. (in Russ.).

4. Beketov V.D. Povyshenie effektivnosti proizvodstva drevesnovoloknistykh plit. [Improving the efficiency of the production of fiberboard]. Moscow, 1988, 160 p. (in Russ.).

5. Volynskii V.N. Tekhnologiia drevesnykh plit i kompozitnykh materialov. [Technology of wood-based panels and composite materials]. St. Petersburg, 2010, 336 p. (in Russ.).

6. Lesnye resursy Rossii. Mezhdunarodnyi transliator natsional'nykh standartov na osnovnye vidy lesnoi produktsii. [Forest Resources of Russia. International translator of national standards for the main types of forest products]. Ed. I.V. Voskoboinikov. Moscow, 1994, 562 p. (in Russ.).

7. Chelysheva I.N. Sovershenstvovanie tekhnologii proizvodstva tverdykh drevesnovoloknistykh plit povyshennoi vodostoikosti : dis. ... kand. tekhn. nauk. [Improving production technologies hardboard increased water resistance: dis. ... Cand. tehn. Sciences]. Krasnoyarsk, 2007, 151 p. (in Russ.).

8. Tekhnologiia tselliulozno-bumazhnogo proizvodstva. V 3 t. T. II. Proizvodstvo bumagi i kartona. Ch. 2. Osnov-nye vidy $i$ svoistva bumagi, kartona, fibry $i$ drevesnykh plit. [Technology of pulp and paper production. In 3 v. Vol. II. Manufacture of paper and paperboard. Part 2. Fundamentals-WIDE types and properties of paper, cardboard, fiber and wood-based panels]. St. Petersburg, 2006, 499 p. (in Russ.).

9. Lomakin A.D. Zashchita drevesiny i drevesnykh materialov. [Protection of wood and wood materials]. Moscow, 1990, 256 p. (in Russ.).

10. Patent 2033489 (RU). 1995. (in Russ.).

11. Ivanov F.M. Biopovrezhdeniia v stroitel'stve. [Biodegradation in construction]. Moscow, 1984, 320 p. (in Russ.).

12. Leonovich A.A. Snizhenie pozharnoi opasnosti drevesnykh materialov, izdelii i stroitel'nykh konstruktsii. [Reduced fire hazard wood-based materials, products and building structures]. St. Petersburg, 2002, 59 p. (in Russ.).

13. Leonovich A.A. Ognezashchita drevesnykh plit i sloistykh plastikov. [Fire wood boards and laminates]. Moscow, 1974, 128 p. (in Russ.).

14. Leonovich A.A. Drevesnye plity spetsial'nogo naznacheniia. [Wood-based panels for special purposes]. St. Petersburg, 2007, 96 p. (in Russ.).

15. Patent 2352601 (RU). 2009. (in Russ.).

16. Rayham E.A. Fire Prot. Rev., 1975, vol. 38, no. 411, pp. 67-74.

17. Shapiro A.D. Sposoby pridaniia drevesnovoloknistym plitam ognezashchitnykh svoistv. [Ways to make wood fiber board fire-retardant properties]. Moscow, 1962, 56 p. (in Russ.).

18. Leonovich A.A. Materialy nauch.-tekh. konf. LTA. [Materials Science and Technology Conference Forestry Academy]. Leningrad, 1966, pp. 64-70. (in Russ.).

19. Certificate of authorship 195626 (USSR). 1967. (in Russ.).

20. Zabrodkin A.G. Novoe v tekhnike i tekhnologii drevesnostruzhechnykh plit. [New in technology chipboard]. Moscow, 1972, pp. 72-76. (in Russ.).

21. Antonov A.V. Proizvodstvo drevesnovoloknistykh plit s ponizhennoi pozharnoi opasnost'iu: dis. ... kand. tekhn. nauk. [Production of fiberboard with high fire danger: the dissertation of the candidate of technical sciences]. Krasnoyarsk, 2013, 128 p. (in Russ.).

\footnotetext{
* Corresponding author.
} 
22. Balakin V.M., Seleznev A.M., Belonogov K.V. Pozharovzryvobezopasnost', 2010, vol. 19, no. 6, pp. 14-19. (in Russ.).

23. Shishlov O.F., Dozhdikov S.A., El'tsov O.S., Ulomskii E.N., Glukhikh V.V., Stoianov O.V. Vse materialy. Entsiklopedicheskii spravochnik. [All materials. Encyclopedic Reference]. 2013, no. 10, pp. 47-55. (in Russ.).

24. Dozhdikov S.A. Poluchenie drevesnykh kompozitsionnykh materialov s kardanolsoderzhashchimi novolachnymi smolami : dis. ... kand. tekhn. nauk. [Production of wood composite materials with Cardanol containing novolac resin Dissertation of the candidate of technical sciences]. Ekaterinburg, 2014, 130 p. (in Russ.).

25. Antonov A.V., Alashkevich Iu.D., Petrusheva N.A., Chizhov A.P. Drevesnye plity: teoriia i praktika: sbornik statei po materialam XIV mezhdunarodnoi nauchno-prakticheskoi konferentsii. [Wood-based panels: theory and practice: a collection of articles on materials of the XIV International scientific and practical conference]. St. Petersburg, 2011, pp. 71-73. (in Russ.).

26. Antonov A.V., Petrusheva N.A., Alashkevich Iu.D. Lesnoi zhurnal, 2012, no. 4, pp. 99-104. (in Russ.).

27. Antonov A.V., Petrusheva N.A., Chizhov A.P., Alashkevich Iu.D. Khimiia rastitel'nogo syr'ia, 2012, no. 4, pp. $215-219$. (in Russ.).

28. Antonov A.V., Petrusheva N.A., Chizhov A.P., Alashkevich Iu.D. Khimiia rastitel'nogo syr'ia, 2012, no. 4, pp. $221-224$. (in Russ.).

29. Antonov A.V., Alashkevich Iu.D., Petrusheva N.A., Chizhov A.P. Novye dostizheniia v khimii $i$ khimicheskoi tekhnologii rastitel'nogo syr'ia: materialy V Vseross. konf. s mezhdunar. uchastiem. [Advances in chemistry and chemical technology of vegetable raw materials: materials V All-Russian conference with international participation]. Barnaul, 2012, pp. 429-432. (in Russ.).

30. Antonov A.V., Alashkevich Iu.D., Petrusheva N.A., Chizhov A.P. Novye dostizheniia v khimii $i$ khimicheskoi tekhnologii rastitel'nogo syr'ia: materialy V Vseross. konf. s mezhdunar. uchastiem. [Advances in chemistry and chemical technology of vegetable raw materials: materials V All-Russian conference with international participation]. Barnaul, 2012, pp. 427-429. (in Russ.).

31. Patent 2486054 (RU). 2013. (in Russ.).

32. Drozdov I.Ia, Kunin V.M. Proizvodstvo drevesnovoloknistykh plit. [Manufacture of fibreboard]. Moscow, 1975, 328 p. (in Russ.).

33. Ivanov S.N. Tekhnologiia bumagi. [Technology papers]. Leningrad, 1970, 695 p. (in Russ.).

34. Steenberg B. Svensk Pappers-tidnirg, 1963, vol. 66, no. 22, pp. 933-939.

35. Chiaverina I. Proceedings of the II the Annual Pulp and Paper Conterence, Kalamaz, 1967, pp. 73-79.

36. Alashkevich Iu.D. Issledovanie gidrodinamicheskikh iavlenii v protsesse razmola volokon $v$ nozhevykh $i$ razmalyvaiushchikh mashinakh: dis. ... kand. tekhn. nauk. [Study of the hydrodynamic phenomena in the process of grinding fiber blades and grinding machines: the dissertation of the candidate of technical sciences]. Leningrad, 1970, 143 p. (in Russ.).

37. Legotskii S.S., Goncharov V.N. Razmalyvaiushchee oborudovanie i podgotovka bumazhnoi massy. [Grinding equipment and preparation of pulp]. Moscow, 1990, 224 p. (in Russ.).

38. Korda I., Libnar Z., Prokop I. Razmol bumazhnoi massy. [Grinding pulp]. Moscow, 1967, 402 p. (in Russ.).

39. Meinander P.O. Tselliuloza. Bumaga. Karton, 2004, no. 8, pp. 11-14. (in Russ.).

40. Patent 5868330 (USA). 1999.

41. Apl. 19547069 (DE). 1997.

42. Clark James D.A. Tappi, 1969, no. 2, pp. 335-340.

43. Pashinskii V.F. Mashiny dlia razmola voloknistoi massy. [Machines for beating the pulp]. Moscow, 1972, 160 p. (in Russ.).

44. Goncharov V.N., Gauze A.A., Alikin V.P. Mashiny dlia rospuska i beznozhevogo razmola bumazhnoi massy. [Machines for the dissolution without knife grinding pulp]. Leningrad, 1979, 106 p. (in Russ.).

45. Ukhanova G.V., Laskeev P.Kh., Liptsev I.V. Sbornik trudov VNIIDrev, 1973, no. 6, pp. 15-19. (in Russ.).

46. Laskeev P.Kh. Proizvodstvo drevesnoi massy. [Manufacture of pulp]. Moscow, 1967, 580 p. (in Russ.).

47. Laptev V.N. Proizvodstvo drevesnoi massy. [Production of wood pulp]. St. Petersburg, 2009, 48 p. (in Russ.).

48. Oblivin A.N. Derevoobrabatyvaiushchaia promyshlennost', 2000, no. 3, pp. 6-11. (in Russ.).

49. Alashkevich Iu.D. Osnovy teorii gidrodinamicheskoi obrabotki voloknistykh materialov v razmol'nykh mashinakh : dis. ... d-ra tekhn. nauk. [Fundamentals of the theory of hydrodynamic processing of fibrous materials in grinding machines: the dissertation of the doctor of technical sciences]. Krasnoyarsk, 1986, 170 p. (in Russ.).

50. Goncharov V.N. Teoreticheskie osnovy razmola voloknistykh materialov v nozhevykh mashinakh : dis. ... d-ra tekhn. nauk. [Theoretical Foundations of grinding fibrous materials in the knife machines: the dissertation of the doctor of technical sciences]. Leningrad, 1990, 433 p. (in Russ.).

51. Liptsev N.V. Teoreticheskie osnovy tekhnologii drevesnovoloknistoi massy i puti povysheniia effektivnosti proizvodstva drevesnovoloknistykh plit : avtoref. dis. ... d-ra tekhn. nauk. [Theoretical Foundations of technology wood-mass and ways to improve the efficiency of production of fibreboard: the Dissertation of the doctor of technical sciences]. Leningrad, 1982, 39 p. (in Russ.).

52. Pen R.Z. Tekhnologiia drevesnoi massy. [Technology pulp]. Krasnoyarsk, 1998, 220 p. (in Russ.).

53. Gur'ianov V.E., Semkina L.I., Psumiakova T.N. Bumazhnaia promyshlennost', 1990, no. 10, pp. 11. (in Russ.).

54. Leonovich A.A. Tekhnologiia drevesnykh plit: progressivnye resheniia. [Technology of wood-based panels: innovative solutions]. St. Petersburg, 2005, 208 p. (in Russ.). 